\title{
All that is Solid: Writing, Reading and Publishing in Post- modern Capitalism
}

\author{
Ben Agger* and Timothy W. Luke** \\ * University of Texas at Arlington, agger@uta.edu \\ **Virginia Tech, twluke@vt.edu
}

\begin{abstract}
This paper is a reflection on the publication practice of the journal Fast Capitalism, an opensource, electronic journal established by Ben Agger and Timothy Luke in 2005. It also presents thoughts on writing, reading and publishing in postmodern capitalism.
\end{abstract}

Keywords: publishing, open access, Fast Capitalism, postmodern capitalism

\section{1. "Fast Capitalism"}

The decision to start Fast Capitalism, an open-source, electronic journal found at www.fastcapitalism.com came out of rejection and frustration. First, Agger's rejection after he had applied for the editorship of the official American Sociological Association journal, Sociological Theory, only to be rejected. Agger never thought he would easily get that editorship, given the interdisciplinary and critical nature of his work in a field that is increasingly formalistic and/or fragmented. Yet, as the adage goes, you definitely will be rejected if you not apply! To be sure, Agger was hesitant about the whole thing because whatever innovative impulse he sought to bring to the subfield would have been highly constrained by institutional and disciplinary constraints ranging from the guild-driven games of double-bind peer review to the disciplinary infatuations with the latest conceptual crazes that are all too often resurrected, revitalized, and then rehashed revisitations of stale theoretical debates. The recent "rediscoveries" of Leninism, Marxism or other orthodox communists as the Great Recession tapers off is but one case in point. Agger was justly fearful that Sociological Theory, even under his editorship, would be boring to keep up the appearances of professional correctness. Luke's frustrations, on the other hand, arose from his exasperations with so many existing print journals had not yet fully made their ways into the digital domain, and probably never would because so many of their authors, editors, and owners remained trapped in the time warps of the 1970s, believing nothing was worth reading unless trees died to bear words in ink to their eyes. Luke believed a "born digital" journal could begin to do scholarly communication differently, since he had been supporting one or two of them in an on-campus "digital discourse center." Agger's work on digital media led him to the same conclusion.

Since we have had ample editorial experience with various print journals and book series, we decided to start our own electronic journal, devoted most centrally to analysis of the impact of new information and communication technologies (ICTs), such as the Internet, on self, society and culture in the 21 st century. We would use the Internet to study the Internet as well as organize others with parallel aspirations. We assembled an international editorial board-global non-positivists who do media and cultural studies of one kind or another. Some very talented graduate students helped design our journal's page and they do the tedious "coding "work that translates Word files to screen text, image and sound. We sought to do more than print, and welcomed multimedia submissions, allowing us frequently to publish video, photos, and music. Our operating budget is exactly zero.

We established several desiderata:

- We would rethink the stale rituals of refereed scholarship.

We believed that the process of double-blind peer review is often merely a political shield, some methodological networking skirmish, or the conceptual cringe of social scientists, hu- 
manists, or critics anxious about their intellectual position in the academy. Whether it is physics or philosophy, double-blind peer reviewing is not objective. Reviewers write from perspective, and editors read reviews from perspective. Picking reviewers isn't objective. There is no Archimedean point, outside of social context, from which any of this labour transpires. We expose submitted papers to multiple sets of eyeballs, but we never pretend that peer review is a value-free, positivist process certain to extrude "excellence" from authors. We question what useful guidance might be gained from repeatedly being thrown into situations of marching in place for months only to be dipped suddenly into execrable episodes of anonymous, acidic and academic hectoring. Reviewing, like editing, is always already undecidable. We recognize that electronic publishing is undergoing various processes of disciplinary valorisation for the purposes of producing new career capital. The physical sciences and traditional humanities, which frequently appear more attentive to media/cultural/Internet studies, often have proven to be further ahead of the social sciences in valorising journals such as Fast Capitalism because they look more fully at "pull" rather than "push" factors in academic communication. That is, how many people read any given paper, at what rate of distribution, in which communities of discourse, and with what general influence rather than in which putatively prestigious publications did this or that work of scholarship appear. Given our intellectual perspective, we do not care about our standing in professional organizations' official organs of publication, approved citation indexes or algorithmic impact assessments. It is nearly impossible to stay invisible in the open, bright domains of the Internet, and the search engines' spiders will find everything that is ready to read.

- We would publish much interdisciplinary work.

As we explore in our ten-year retrospection, below, some authors are more deeply invested in discipline than are others, who have more diffuse, and multiple, identities. Critical theory/cultural studies people like us are more likely to have diffuse and multiple identities, being everywhere and nowhere at once. Our academic training and uneven career trajectories reflects this heterogeneity. Authors more invested in discipline have plenty of publication outlets available to them.

- We would publish both established people and emerging younger academics.

We were graduate students and entering assistant professors once! Getting published is thrilling as well as necessary. We work with younger scholars in developing their papers. They seek us out in part because we are interdisciplinary and in part because they are more likely to valorise electronic publication.

- We would focus on cultural and political issues that bridge the social sciences and humanities.

The model of the 19th century German university, transplanted to the U.S., is fine for disciplinary scholars, a point we take up below, but thwarts people who have diffuse, multidisciplinary and interdisciplinary identities. There are few departments or programs in cultural studies, and none in critical theory-our affiliations and identities. Our editorial board is heterogeneous with respect to discipline and nationality. Like the prior generations of Frankfurter Schule scholars who inspired us, we reject the distinction between theory and empirical research but instead regard theory as writing that occurs at 30,000 feet, affording panoramic perspective. Such grand narratives may lack ground-level detail, and so we welcome smaller, less panoramic narratives in the papers we edit and publish.

- We would edit with a certain political intent.

If there are two kinds of scholars, Newtonian positivists who stand outside the world and reflect it without perspective, prejudice and passion, on the one hand, and 11th Thesis people, on the other, we are plainly standing with the latter. Like Marx and western Marxists, we do not relinquish rigorous objectivity, but we regard value-free scholarship as a tired trope of professional correctness that conceals many conflicted political ontologies in the more secret network warfare of methodologies and means hidden in the reading/writing of "the scientific 
method." Subscribing to the 11th Thesis-the point is to change the world by knowing itdoes not mean that we do not have putative standards, or fail to subject papers to multiple readings. We have no party line, as our extremely diverse offerings demonstrate. We tend to favour work that treats of the interface of culture, very broadly understood, and power.

What of the future? The Internet will undoubtedly avoid the faddish fate of the hula-hoop and microfilm as it has become deeply embedded in the fabric of a global capitalism and culture industries. It surely will evolve as connectivity becomes more widespread, especially in the Third World. The laptop and mobile wireless device are the new means of production as well as of diversion. For these reasons, electronic publishing is here to stay. The crisis in print publishing reflects the massive migration of writing, reading and editing online, and we recognize that these communicative occasions are also the events marking the decline of libraries, bookstores and newspapers. We do not celebrate the relative eclipse or actual demise of many scholarly media, and we agree with Habermas and Jacoby that a democratic public sphere requires a vibrant intellectual life. Starbucks has not replaced the British Museum's reading room, although it is becoming apparent that much more intellectual work is unfolding in outlets of the former than at the desks of the latter as the intellectual life goes more and more online to be conferenced, discussed, even edited.

When we started the journal in 2005 , we wrestled with legitimation problems confronting a fledgling electronic journal. We need not have worried. Nearly a decade later, pulp is rapidly giving way to pixels. Many publishers and authors realize that online publication is much less expensive, potentially global, downloadable and nearly instantaneous. Journals that are making the transition wonder if they even should continue to print paper editions. Intellectual property issues present challenging problems for indie authors and artists trying to make a living without becoming salaried academic civil servants or working for advertising agencies. And because we recognize the vitality and resilience of multiple media for any economy or society, we do not celebrate the demise of libraries and newspapers, which provide depth, room and time for contemplation and, in the case of books, a spine. Being bound matters because books can be endlessly read and reread in a way that the ever-changing Internet often denies. Bookmarking a web site is different from owning or borrowing a book or journal.

We care less about the more recently established professional organizations' outlets for electronic journal publishing because, frankly, most of these academic journals, beyond their abstracts, are written for tenure and advancement, not to be read. Public intellectuals can circulate their essays in many outlets, but to see the light of day in officially refereed academic journals takes enormous time and intellectual compromise as carping reviewers do not respect the idea that discourses are ensconced in language games that have their own sense and sentience. In other words, many reviewers want the author to have written the piece their way, reflecting a literary will to power that makes a mockery of Mill's marketplace of ideas and Habermas' ideal speech situation. We do not edit that way but work with authors to polish arguments with which we may not agree, enabling them to fulfil their textual potential in their own terms. Again, the matter of the will to power.

Below, we reprint our retrospection on the first nearly ten years of Fast Capitalism. It is fair to say that we were surprised by, in Hegel's sense, recognition. It is difficult to stay invisible on the Internet. Perhaps the times were and are right for an electronic journal about electronic cultures, politics, and power. We never considered restricting access, with a pay portal. Our budget is non-existent, and we do not seek institutional support beyond Internet hosting. As the Frankfurt School cadre realized when they struggled to establish and sustain the Institute for Social Research outside of the bourgeois university, autonomy is priceless.

Nearly a decade after we began, we no longer have to call for papers. They flow in, from all corners of the globe. Our authors, although eclectic in training, home discipline and methodologies, are likely to be able to complete the phrase, which serves as our title: "All that is solid..."! Authors find journals readily, using search engines, hyperlinking, and sheer word of mouth (or pixelated word). We have become self-sustaining, although there is a certain fragility in our Internet dependence, but perhaps no more fragility than in the pulp publishing industry, which requires product and profit. 


\section{2. "Getting to Ten" - Preface to issue FC10.1 (www.fastcapitalism.com)}

Ben Agger and Timothy W. Luke

Nearly a decade ago on the eve of the Great Recession, we believed that new publishing possibilities afforded to anyone with sufficient Internet connectivity and enough intellectual contacts provided an outlet for the historical sociology, cultural studies, political economy, and aesthetic criticism that anchors critical social theory. Older existing print journals had not yet fully made their ways into the digital domain, and maybe some of them never would.

What could a "born digital" journal begin to do scholarly communication differently? How might it create new intellectual networks? Who would join its experiments from across the academy, around the world, and alongside the established media ecologies of print journals? Running with this sense of curiosity, and pushing ahead with a willingness to give it a try on "Internet time," Fast Capitalism journal posted its 1.1 issue in 2005 - about seven years after eBay went public, one year after Google's IPO, the year Facebook.com began to grow after relocating its offices to Silicon Valley, two years before the first generation iPhone, and five years before the first generation iPad.

In this milieu, our journal was born of excitement about interdisciplinary critical theory and cultural studies, and frustration about existing so-called peer reviewed traditional disciplinary journals. There are two types of faculty - those with strong and singular disciplinary identities (e.g., chemist, economist, psychologist) and others of us with diffuse and multiple identities, such as cultural studies, media analysis, and critical theory. We are at home nowhere and everywhere, and this is an outlet for people like us. Our editorial board reflects the fact that most of us are willingly of the second type, working actively across, and between, disciplines. Fast Capitalism not only bridges disciplines; it connects social, political, and cultural studies. As well, we were frustrated by traditional so-called refereed journals that use the bureaucratic rituals and scientistic pretenses of peer reviewing as a political shield. We are convinced that editing is far more undecidable authorial work, which is to say that editors have a great deal of control over what they publish-choosing reviewers, reading and interpreting reviews, passing advice back to authors, making final editorial decisions. The process is far from objectively grounded in Platonic notions of quality, rigor or merit. It is, as all readings are, political. We resist the professionally correct editorial will to power, which pretends that there is an Archimedean standard of quality that is external to the busy, muddy literary work that underlies intellectual life. As Derrida said, there is nothing outside the text, by which he meant that it is impossible to escape the prison house of language, first identified by Nietzsche. Paraphrasing Merleau-Ponty, where he acknowledges the difficulty of predicting the timing of a socialist revolution, editorial standards are not written indelibly on any wall nor inscribed in a metaphysical heaven. Instead we stand with Nietzsche, we sit with the Frankfurt School, we run with the French insights about texts, writing and reading, and we walk with McLuhan into new media environments. What we publish here reflects our frustration with (call it) the professionally correct codes of positivist editing, disciplinary dictates, and methodological fetishism.

Whether authors who publish in our pages can garner career capital is somewhat beside the point. They now seem intent on expressing "the sociological imagination" C. Wright Mills bid us to discover for everyone rather set upon assembling a portfolio of so-called "high impact factor" articles required for their individual promotion and tenure in the future. Certain U.S. disciplines, such as English, more quickly validated electronic publication than have some of the still quite traditional social science disciplines. Inasmuch as it is nearly impossible to remain invisible on the Internet, we suspect that our articles have impact, even as they may fall through the cracks of disciplinary valorisation tied to print capitalist paper journals for hiring, tenuring and promoting purposes. Perhaps in ten years, most of us will be driving down the road in semi-autonomous hybrids, and, similarly, books and articles will be issued mainly, or only, in electronic form. The crisis of book publishing certainly suggests this possibility. 
Moving the journal from an idea into actual implementation amid what was then uncertain acceptance of purely digital content; we believed Fast Capitalism would be a test for the wide-open possibilities of "open source" scholarly publishing. The contradictions created by greater connectivity and multiple scholarly communities becoming trapped in the intellectual property rights regime of print capitalism were, and still are, quite real. The chance to get new ideas to more people even faster, while maintaining a sense of a free intellectual commons, had been possible for nearly a decade. Yet, too few were truly trying something new. Clearly, Fast Capitalism's authors and audiences have been frustrated by the overly compartmentalized and strangely disciplinary leanings of far too many established print outlets as they fumbled around in search of their paths through these evolving publication possibilities. No longer wanting to watch and wait, we launched Fast Capitalism as an exploration in open source, multi-media, mixed method, and cross-disciplinary discourse to speak from the Left to any who would listen. Taking "fast capitalism" as its title from Agger's 1989 book with the University of Illinois Press, the journal has endeavoured in many respects to be a rapid response force for the critique of that political economy and sociology that Luke's 1989 book, also with the University of Illinois, saw at work on the "screens of power." It is fitting that our journal then is available first and foremost on the screen.

As we anticipated in Year Zero of the post-Cold War terrains of the "New World Order," the organic connections between accelerating, expanding, and intensifying fast-capitalist exchange and the seductive, secretive, and selective screening of power have only become more fascinating and significant over the past quarter century as many new nations and economies have become ensnared in their constant contact with $24 \times 7$ transnational exchange in the development of actually existing neoliberalism. While some academic journals and a few engaged sites of critical discourse did address their import, none did so with the eclectic scope and effective focus we believed was necessary. After the dismal re-election of George W. Bush in 2004, the reckless choice by the U.S. and its "coalition of the willing" to go to war in Iraq in 2003, the loss of that coalition's sense of mission for the Afghan intervention in 2002, the shocking Al Qaeda terrorist attacks in 2001, and the miserable institutional failures experienced during 2000 by the "world's sole remaining superpower" in the Bush/Gore presidential contest as well as the popping of the dotcom economic bubble, 2005 definitely seemed like an opportune moment to wade into the flow of discourse rising on the Internet in e-journals, web logs, e-books, and listservs. It was time to consider the uncommon crises that the U.S. and the world at large have been confronting in the 21 st century.

With little institutional support beyond a bare minimum bandwidth provision, software application support, benign silent tolerance, and occasional news releases from our home campuses at the University of Texas-Arlington and Virginia Polytechnic Institute \& State University, Fast Capitalism launched the 1,1 issue during late summer 2005 after several months of preliminary development and extended discussion about the media ecologies of this moment. Using standard simple HTML constructs, deploying a few flash pages juxtaposing images of contemporary capitalism, the journal used images, sound, music, and movement to introduce old and new generations of authors to new audiences in the Anglophone infosphere just as more mobile wireless devices began populating increasingly ubiquitous computing environments. Matthew Levy designed the journal, keeping its look spare and to the point. Noah Kersey has assumed the managing editorship, and does the arduous coding work that makes publication possible. He is our means of production.

Some Fast Capitalism writers have been at their trade since the 1960s, while others published their first articles as intellectuals in Fast Capitalism in the 2000s. Even though it is posted in the U.S., the journal is a global publication that has invited contributions from around the world as well as taken up topics of concern in every corner of the world. The writing is political and critical, but it also can be introspective and reflective as authors think through questions of theory and practice, rationality and emotion, order and disorder, personality and society.

Like many journals, it expresses the personal interests, professional networks, and political engagements of the editors, its advisory board, and the authors who publish in it. Yet, it also has captured, if only in part, many events that have marked the contours of the past 
decade. Like 10.1, issue 1.1 was anchored by a major multimedia work organized by Robert Goldman, and this initial number investigated the technocultures of speed, power, and capital. 2.1 in 2006 continued this interest with another collection of contributions on technocapitalism and its destructively creative practices. In early 2007, 2.2 examined animal rights, the critical theory of nature developed by William Leiss, and other questions of environmental order/disorder. The concerns of textuality and new media preoccupied 4.1 in 2008 , while 5.2 in 2009 looked into the dynamics of social media like Facebook. Issue 6.1 in 2009 was a special examination of narrative, biography, and identity with elaborate online art presentations and works of reflective writing. The global economic crisis was at the centre of 7.1 in 2010, and 8.1 in 2011 was another special issue tied to studies of Slovenia, the European project, and crisis-ridden capitalism. The disruptive role of new media in the academy concerned many of the pieces in 8.2 during 2011, while the implications of the global "Occupy Wall Street" movements tied together many of the studies presented in 9.1 during 2012.

Along the way, two other issues - 3.1 in 2007 that focused on the April 16, 2007 shootings at Virginia Tech and 5.1 in 2009 that reflected back on the influence of Paul Piccone and his journal Telos in "the Americanization of critical theory" since the 1960s - were quickly picked up by established publishing houses to appear as bound print books respectively in 2008 and 2011. The Virginia Tech book was issued by Rowman \& Littlefield, and the book on Piccone's legacy appropriately appeared under the imprint of Telos Press. Likewise, issue 10.1 initially was planned around the theme of "gun violence and public life" in the wake of the 2012 shootings at Sandy Hook Elementary School in Newton, Connecticut, but this compendium of papers went instead directly into production as a bound book with Paradigm Publishers.

What comes next is always difficult to foretell, but there will be a Fast Capitalism 11.1. To get there, and beyond, we invite you to join the debates that have unfolded here for nearly a decade.

\section{About the Authors}

Ben Agger

is professor of sociology and humanities at the University of Texas at Arlington. He is editor of Fast Capitalism (http://www.fastcapitalism.com) and author of books such as "Texting toward Utopia: Kids, Writing, and Resistance" (2014), "Oversharing: Presentations of Self in the Internet Age" (2012), "Speeding Up Fast Capitalism" (2004), "The Virtual Self" (2003), "Critical Social Theories: An Introduction” (2014, $3^{\text {rd }}$ ed.), “Cultural Studies as Critical Theory” (1992)”, “Fast Capitalism” (1989).

Timothy W. Luke

is University Distinguished Professor of Political Science at Virginia Polytechnic Institute and State University in Blacksburg, Virginia as well as the founding co-director of the Center for Digital Discourse and Culture (CDDC) and the Alliance for Social Political Ethical and Cultural Thought in the College of Arts and Sciences, and later the College of Liberal Arts and Human Sciences, in Blacksburg 